\title{
Study on Shear Angle Model for Superalloy GH4169 Zhong-fei Zou ${ }^{1}$,Lin He ${ }^{2,}{ }^{*}$ and Yue-wei Chen ${ }^{1}$ \\ ${ }^{1}$ College of Mechanical Engineering, Guizhou University, China \\ ${ }^{2}$ Guizhou Normal College, China
}

Keywords: Shear Angle, Superalloy, GH4169, Friction Coefficient.

\begin{abstract}
Shear angle is an important parameter to study cutting deformation. This paper uses orthogonal cutting force test to obtain the tangential force and normal force in order to investigate the average friction coefficient on the rake face in machining super alloy GH4169. With high temperature Split-Hopkinson pressure bar (SHPB) compression test, the constitutive equation for GH4169 was established and provided material model for Third Wave Advant Edge software in order to improve the simulation precision. Comparing simulated and calculated results, it is shown that the calculated results are bigger than the simulated ones. Finally, by modifying the shear angle model, we obtain a new model, as well as simulation for its validation. The new shear angle model proves out more suitable to express the shear angle in the cutting process of super alloy GH4169.
\end{abstract}

\section{Introduction}

As is known to all, the shear angle is the angle between the shear plane and the cutting speed. It can directly reflect cutting deformation. So it is an important parameter to study cutting mechanism. The shear angle not only affects the deformation of chip, the stress distribution on the rake face and the contact length of tool-chip, but also affects the cutting force and the surface quality of work piece[1,2].

During the early works, Ernst [3] and Merchant [4] focused on shear angle considering forces in the shear plane and on the tool-chip interface. With the development of plasticity theory, multiple slip-line models of orthogonal cutting was established [5, 6, 7]. After that, some researchers presented thermo-mechanical theories [8]. Furthermore, a great number of finite element software was appliedto numerical methods [9]. Though there is important development in metal cutting theory, but a key problem that a comprehensive analytical method to determine shear angle has not been solved.

Some researchers from Hefei University of Technology designed a quick stop device to measure the shear angle [10]. But the experimental value is smaller than the calculated value. In addition, there may be many external factors which lead to errors in the measurement process. Besides, the superalloy is expensive, it will increase cost to get the shear angle through experiment. Therefore, finite element analysis become more popular [11, 12]. However, there exists some deviations between the calculated shear angle and the simulated one. Hence, this paper focuses on establishing a new shear angle model. We measure the cutting force by experiment and calculate the shear angle. Meanwhile, the simulation shear angle is obtained by Third Wave AdvantEdge software. Comparing simulated and calculated results, it is shown that the calculated results are bigger than the simulated ones. Finally, by modifying the shear angle model, we obtain a new model, as well as simulation for its validation. The new shear angle model provesout more suitable to express the shear angle in the cutting process of superalloy GH4169.

\section{Analysis of Shear Angle Model}

Many scholars have proposed various hypotheses and models to analysis and studythe cutting angle in the cutting process. Some quite famous models are Merchant, Lee-Shaffer, Shaw and Oxley Model of shear angle. But these model are derived under general cutting speed, without considering the impact of high-speed cutting. According to the principle of power balance [13], the shear angle relation can be deduced considering high speed cutting.In the cutting process Fig.1, the 
shear force is $\mathrm{F}_{\mathrm{S}}$, the cutting layer material go through the shear plane along the shear slip to form shear angle $\varphi$. Then the momentum change need a force $\mathrm{F}_{\mathrm{m}}$. The resultant force of friction force $\mathrm{F}_{\mathrm{f}}$ and normal force $\mathrm{F}_{\mathrm{nf}}$ on the rake face $\mathrm{isF}_{\mathrm{rf}}$. The resultant force of shear force $\mathrm{F}_{\mathrm{s}}$ and normal force $\mathrm{F}_{\mathrm{ns}}$ on the shear plane is $\mathrm{F}_{\mathrm{rs}} \cdot \mathrm{F}_{\mathrm{rf}}$ and $\mathrm{F}_{\mathrm{rs}}$ are balance.

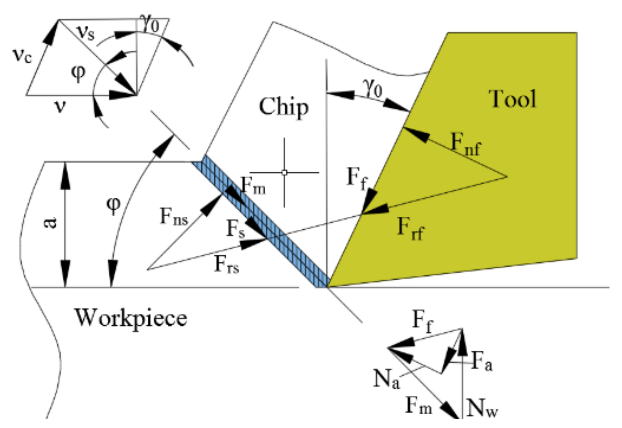

Figure 1. Schematic of shear angle and cutting force

Hence, we firstly assume that the tool does not move, according to the principle of power balance, relationship is established as follows:

$$
\left(F_{n s} \sin \phi+F_{s} \cos \phi\right) v d t+v_{c}^{2} d m / 2=v^{2} d m / 2+F_{s} v_{s} d t+\mu N v_{c} d t
$$

Where, tiny chip mass $d m=\rho A_{c} v d t . \rho$ is the workpiece density, $A_{c}$ is the shear layer area, $v_{,} v_{c}$ and $v_{c}$ denote cutting velocity, chip velocity and shear velocity, respectively. $\mu$ is the friction coefficient, $\gamma_{0}$ is the rake angle, $\mathrm{N}=\mathrm{N}_{\mathrm{a}}+\mathrm{F}_{\mathrm{nf}}$ is the resultant force on the rake face. On the left of the equation, the first item is the work thatthe tiny unit goes through the shear plane, the second is initial kinetic energy of tiny chip mass. On the right of the equation, the first item is kinetic energy when tiny chip mass flow out, the second is shear work caused by unit deformation, the third is friction work caused by tool-chip contact.

Then assume that the workpiece does not move, and the relationship is as follows:

$$
N\left(\cos \gamma_{0}+\mu \sin \gamma_{0}\right) v d t=v_{c}^{2} d m / 2+F_{s} v_{s} d t+\mu N v_{c} d t
$$

Where, on the left of the equation, the first item is the work that cutting tool moves some distance $v d t$.Eq. 3 can be obtained after simplified:

$$
\varphi=\pi / 4-\beta / 2+\left.{ }^{2}\right|^{2}
$$

According to the principle of power balance, we derived the relationship among shear angle, rake angle and friction angle. Apparently, its form is same to Merchant shear angle formula based on the minimum energy principle at low speed. But Eq.3 is also suitable for high cutting speed. It just can be used for qualitative analysis. Based on Eq.3, a new shear angle formula will be established.

\section{Experiment}

In order to determine the cutting force in the cutting process and get the average friction coefficient on the rake face, the cutting force test must be carried out. Dynamometer Kistler-9257 is installed, and reasonable cutting test platform is built. Cutting speedv $=30 \sim 95 \mathrm{~mm} / \mathrm{min}$, depth of 
cut $a_{p}=1.5 \mathrm{~mm}$, feed rate $f=0.15 \mathrm{~mm} / r$.

\section{Finite Element Numerical Analysis}

\section{Material Constitutive Model}

According to dynamic compression test, the constitutive equation of Superalloy GH4169 was developed to describe the relationship among stress, strain, strain rate and temperature. The constitutive equation is as follows [14]:

$$
\sigma=\left(421+1224 \varepsilon^{0.54}\right)[1+0.0192 \ln (1+\dot{\varepsilon})]\left[1-(T-293 / 1300)^{1.27}\right]
$$

The above constitutive equation is used as the simulation material model, and the finite element software Third Wave AdvantEdge is used to simulate the cutting process. This model adapts the updated Lagrangian finite element formulation with continuous meshing and adaptive meshing techniques. We selected four shear angle simulation results. The effective stresses in the rake face and the formation of shear angles are observed in the simulation as shown in Fig. 3.

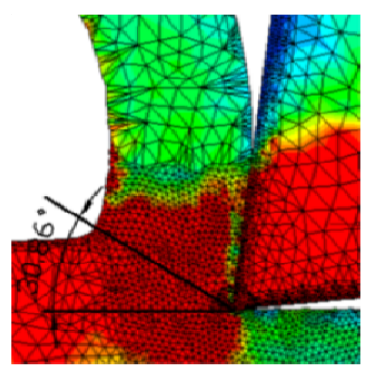

$\mathrm{V}=30 \mathrm{~m} / \mathrm{min}, \varphi=30.86$

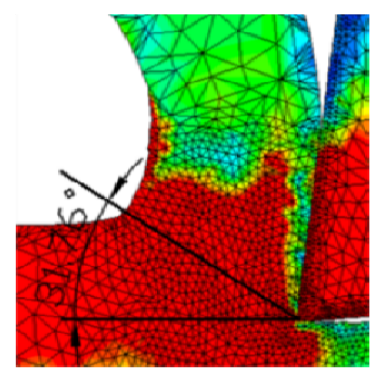

$v=60 \mathrm{~m} / \mathrm{min}, \varphi=31.76$

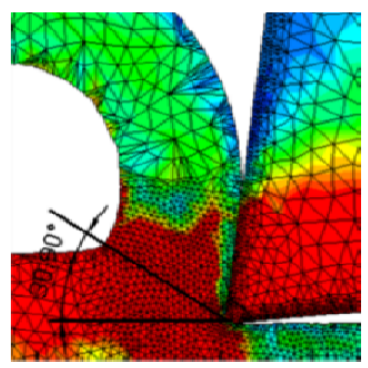

$\mathrm{V}=65 \mathrm{~m} / \mathrm{min}, \varphi=30,90$

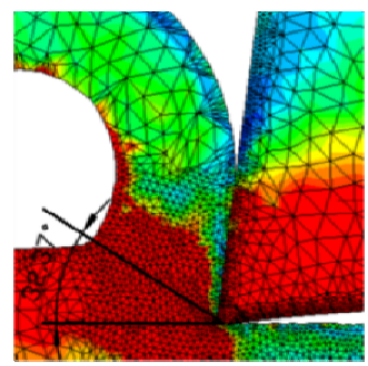

$\mathrm{V}=95 \mathrm{~m} / \mathrm{min}, \varphi=32.37$

Figure 3. Measurement of shear angle obtained by numerical simulation

\section{Results and Discussion}

\section{Friction Coefficient and Friction Angle}

In the cutting process, the friction coefficient on the rake face is always changing. Metal internal friction is larger than external friction. So this paper focuses on internal friction. Assume that $\mu$ is the average friction coefficient on the rake face, according to the law of friction, we obtain:

$$
\mu=\underset{F_{f}}{/} F_{n f}, \beta=\arctan \mu
$$

According to the cutting force test, the influence of cutting speed on friction coefficient and friction angle can be obtained, as shown in Fig.4. It can be seen that the friction coefficient and friction angle decrease with the increasing cutting. 


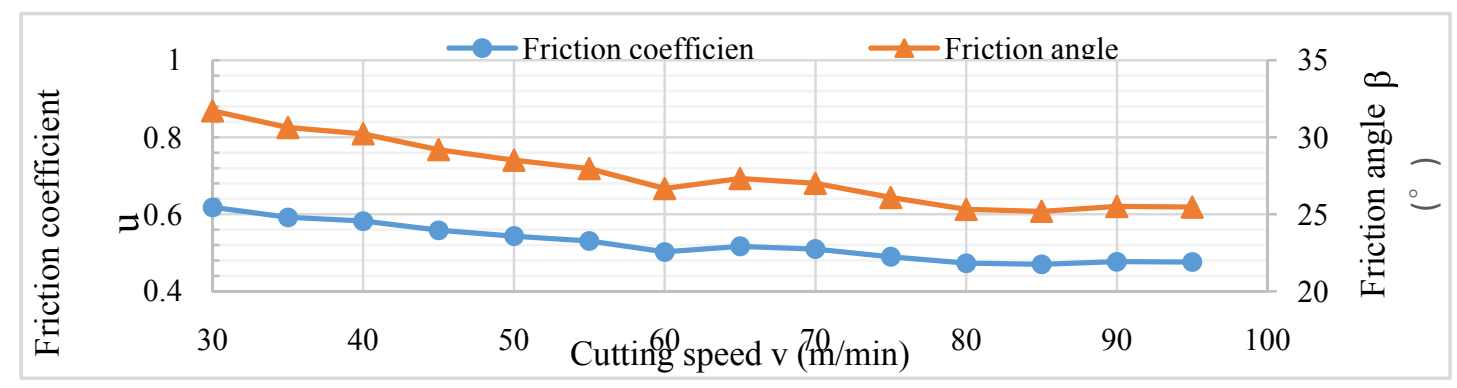

Figure 4.Influence of cutting speed on friction factor and friction angle

\section{Establishment of Shear Angle Model}

Substituting rake angle and friction angle into Eq.3, and comparing calculated and simulated shear angle, results are shown in Fig.5.

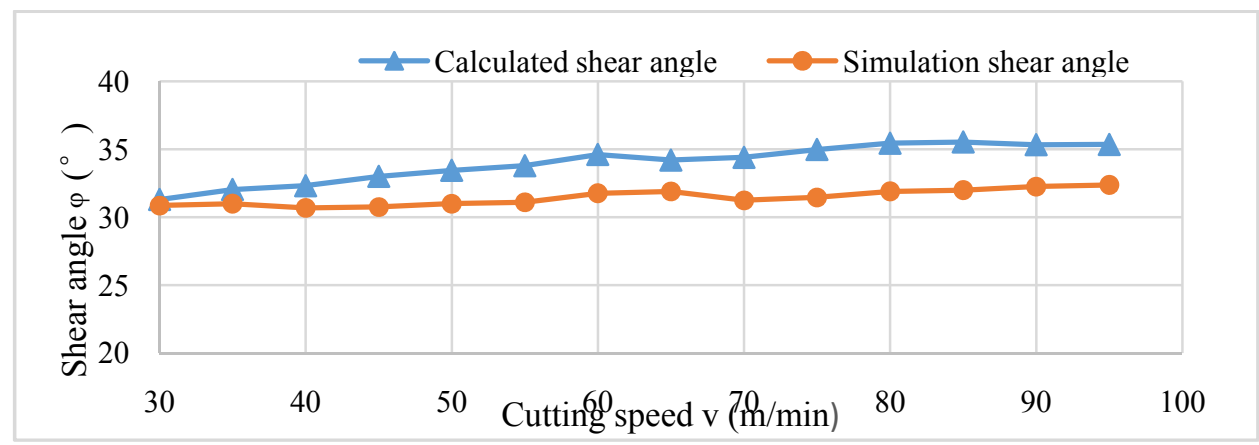

Figure 5.Comparison of shear angle values by different methods

We can observe that the calculated values are bigger than simulated ones. Deviation between calculated and simulated values are listed in Table 3.Obviously, the two methods are inaccurate to express shear angle. Hence, we will make a modification to shear angle model.

Table 3. Deviation between calculated and simulated values

\begin{tabular}{|c|c|c|c|c|c|c|c|c|c|c|c|c|c|c|}
\hline $\begin{array}{c}\text { Cutting speed } \\
(\mathrm{m} / \mathrm{min})\end{array}$ & 30 & 35 & 40 & 45 & 50 & 55 & 60 & 65 & 70 & 75 & 80 & 85 & 90 & 95 \\
\hline $\begin{array}{c}\text { Shear angle } \\
\text { deviation }\left({ }^{\circ}\right)\end{array}$ & 0.43 & 1.04 & 1.63 & 2.24 & 2.44 & 2.69 & 2.85 & 2.30 & 3.16 & 3.52 & 3.55 & 3.54 & 3.07 & 2.99 \\
\hline
\end{tabular}

Assume that we simply focus on the influence of cutting speed on the shear angle, and the shear angle deviation can be regarded as a function of velocity, then the Eq.3 can be corrected as:

$$
\varphi=\pi / 4-\beta / 2+\gamma_{0} / 2+y(v)
$$

By fitting the shear angle deviation value, we can get a reasonable function of deviation trend. Fitting curve and formulas are shown in Fig.6, and the new shear angle formulasare expressed as:

$$
\varphi= \begin{cases}\pi / 4-\beta / 2+\gamma_{0} / 2-8 \times 10^{-5} x^{3}+8.4 \times 10^{-3} x^{2}-0.1691 x+0.1462, & v \in[30,65) \\ \pi / 4-\beta / 2+\gamma_{0} / 2+2 \times 10^{-4} x^{3}-4.41 \times 10^{-2} x^{2}+3.8544 x-107.44, & v \in[65,95]\end{cases}
$$



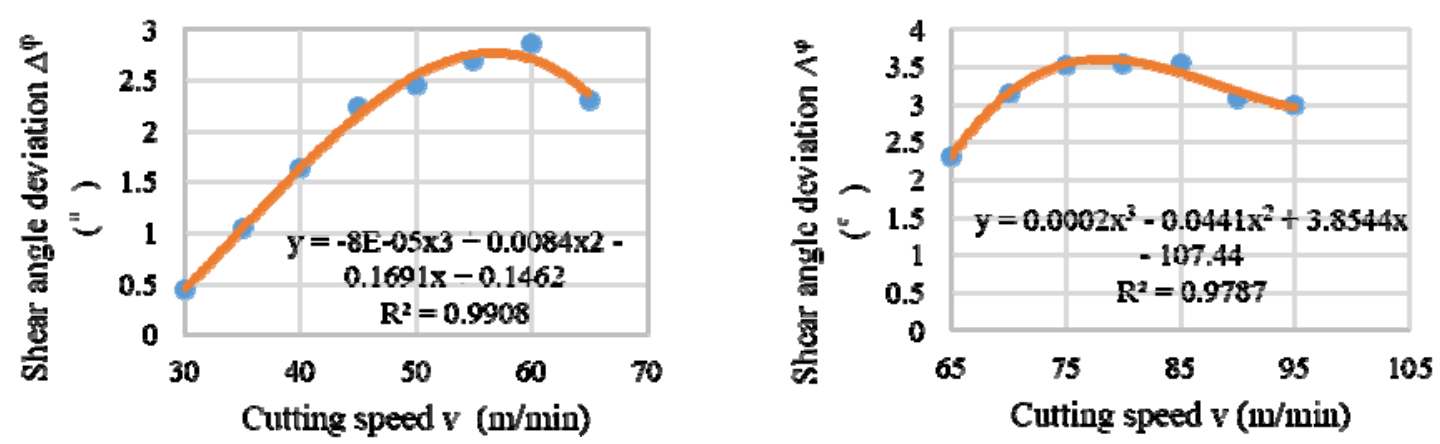

Figure 6.Deviation fitting curves and formulas under different cutting speeds

On the right side of Eq.8, the last item is a function of the shear angle deviation in different velocity ranges.It is a modification to the original shear angle formula.

\section{Conclusions}

(1)In cutting process, the shear angle is not only related to the rake angle, but also the cutting speed and workpiece material.

(2)By means of auxiliary test and finite element simulation, the influence of cutting speed on friction coefficient and shear angle is studied for superalloy GH4169 in cutting process. Results indicate that the friction coefficient decreases and the shear angle increases with the increasing cutting speed. When the cutting speed is more than $80 \mathrm{~m} / \mathrm{min}$, the friction coefficient tends to be stable.

(3)Based on the traditional shear angle model, the traditional model is modified with experimental calculation and simulation, and a new shear angle model is established for superalloy GH4169.

\section{Acknowledgement}

The authors gratefully acknowledge the financial support from National Natural Science Foundation of China (51265005)

\section{References}

[1] J. van der Geer, J.A.J. Hanraads, R.A. Lupton, The art of writing a scientific article, J. Sci. Commun. 163 (2000) 51-59.

[1] W. Ma, X.Y. Chen, F. Shuang, The chip-flow behaviors and formation mechanisms in the orthogonal cutting process of Ti6Al4V alloy, J. Mech. Phys. Solids. 98(2017) 245-270.

[2] R. Bejjani, M. Balazinski, H. Attia, P. Plamondon, G. L’Éspérance, Chip formation and microstructure evolution in the adiabatic shear band when machining titanium metal matrix composites, Int. J. Mach. Tools Manuf. 109(2016)137-146.

[3] H. Ernst, Physics of Metal Cutting, Machining of Metals, ASM, Cleveland, 1938, pp. 1-34.

[4] M.E. Merchant, Basis mechanics of the metal-cutting process, J. Appl. Mech. 11 (1944) A168-A175. 
[5] E.H. Lee, B.W. Shaffer, The theory of plasticity applied to a problem of machining, J. Appl. Mech. 18 (1951) 405-413.

[6] H. Kudo, Some new slip-line solutions for two-dimensional steady-state machining, Int. J. Mech. Sci. 17 (1965) 43-55.

[7] N. Fang, I.S. Jawahir, P.L.B. Oxley, A universal slip-line model with non-unique solutions for machining with curled chip formation and a restricted contact tool, Int. J. Mech. Sci. 43 (2) (2001) $557-580$.

[8] A. Toropov, S.L. Ko, Prediction of shear angle for continuous orthogonal cutting using thermo-mechanical constants of work material and cutting conditions, J. Mater. Process. Technol. 182(2007)167-173.

[9] H. Wang, S. To, C.Y. Chan, C.F. Cheung, W.B. Lee, Elastic strain induced shear bands in the micro cutting process, Int. J. Mach. Tools Manuf.50 (2010) 9-18.

[10]X.L. Fu, X. Ai, Z. Q. Liu, Y. Wan, Study on shear angle model of aluminum alloy 7050-T7451 in high speed machining, Chin. Mech. Eng. 18(2007)220-224.

[11] W.B. Lee, H. Wang, C.Y. Chan, S. To, Finite element modelling of shear angle and cutting force variation induced by material anisotropy in ultra-precision diamond turning, Int. J. Mach. Tools Manuf.75(2013) 82-86.

[12] L.M.B. Araújo, F.J.G. Silva, R.D.S.G. Campilho, J.A. Matos, A novel dynamic holding system for thin metal plate shearing machines, Rob. Comput. Integr. Manuf. 44(2017)242-252.

[13] R.F. Recht, A Dynamic Analysis of High-speed Machining, High Speed Machining. New York, ASME, 1984, pp. 83- 93.

[14] J. Zhou, R.D. Han, Experiment study of green high-speed turning nickelbased superalloy GH4169 [J], Appl. Mech. Mater. 26-28(2010)1132-1136. 